\title{
A French survey of 3,225 patients treated with CPAP for obstructive sleep apnoea: benefits, tolerance, compliance and quality of life
}

\author{
N. Meslier*, T. Lebrun+, V. Grillier-Lanoir*, N. Rolland+, C. Henderick+, J-C. Sailly+, J-L. Racineux*
}

\begin{abstract}
A French survey of 3,225 patients treated with CPAP for obstructive sleep apnoea: benefits, tolerance, compliance and quality of life. N. Meslier, T. Lebrun, V. Grillier-Lanoir, N. Rolland, C. Henderick, J-C. Sailly, J-L. Racineux. CERS Journals Ltd 1998.

ABSTRACT: The aim of this study was to investigate in a large population of patients with obstructive sleep apnoea and on long-term treatment with continuous positive airway pressure (CPAP) the patients' perception of symptomatic improvement, side-effects and quality of life.

Questionnaires were mailed via local respiratory homecare associations to 5,339 French patients who had been treated at home for at least 6 months with CPAP machines and who continued their treatment.

In total, 3,225 questionnaires were analysable. More than $80 \%$ of the responding patients reported that CPAP treatment had greatly improved their symptoms. Despite discomfort related to nasal problems and excess noise from the blower, the mean rate of use for the whole population was $6 \mathrm{~h} 36 \mathrm{~min} \pm 2 \mathrm{~h} 15 \mathrm{~min}$. The perceived health evaluated by the Nottingham Health Profile was good (mean score $<50$ ) for at least $75 \%$ of the patients in each dimension explored. The perceived health was significantly related to the improvement in symptoms, the overall satisfaction and the objective compliance.

This retrospective study indicates that patients who continued continuous positive airway pressure treatment for more than 6 months felt a great improvement in their symptoms, were satisfied with the treatment and had a relatively good perception of their health.

Eur Respir J 1998; 12: 185-192.
\end{abstract}

\begin{abstract}
* Service de Pneumologie, Centre Hospitalier Universitaire Angers, France. ${ }^{+}$CRESGE (Centre de Recherches Economiques Sociologiques et de Gestion), Université Catholique de Lille, France. $¥$ ANTADIR (Association Nationale pour le Traitement à Domicile des Insuffisants Respiratoires), Paris, France.

Correspondence: N. Meslier, Laboratoire d'EFR et de Sommeil, Service de Pneumologie, CHU, 4 rue Larrey, 49033 Angers Cedex 01, France

Fax: 33241353583

Keywords: Compliance, long-term treatment, nasal continuous positive airway pressure, quality of life, tolerance

Received: August 261997

Accepted after revision April 21998

This study was performed by ANTADIR with support from the Ministry of Research and Technology in the domain of "Economic evaluation of prevention and treatment strategies". Financial support was also provided by the National Social Security Office (CNAM) and CFPO, Pierre Medical and SEFAM companies.
\end{abstract}

Since its first description in 1981 [1], nasal continuous positive airway pressure (CPAP) has become the treatment of choice for patients with obstructive sleep apnoea syndrome (OSAS). Its therapeutic efficacy has been clearly demonstrated. Nasal CPAP eliminates apnoea, hypopnoea and snoring, and improves sleep quality and the symptoms of OSAS, above all the excessive daytime sleepiness [2-5]. Long-term compliance with nasal CPAP has been reported to range $65-90 \%[3,6-14]$ and $8-28 \%$ of the patients refuse the treatment after a one-night trial of nasal CPAP [10-12].

The use of nasal CPAP is often associated with complaints of nasal problems, noise from the blower and the inconvenience of the treatment related to the CPAP machine and the nasal mask $[9,15,16]$. These side-effects and constraints may affect the compliance [7, 16]. However, one important factor influencing the compliance is the perception of benefits by the patient [9] and particularly the improvement in daytime sleepiness [7, 10, 16]. Patients with OSAS have also been reported to have a deterioration of general health status [17], and an improvement in their perceived health status and quality of life might also influence the compliance with nasal CPAP.

Nasal CPAP was introduced in France in 1985. Since that time, the number of patients treated with nasal CPAP at home has increased dramatically. For a large number of patients, once the CPAP treatment has been prescribed by a physician, the CPAP device is provided to the patient by a local association for home care of patients with respiratory disorders. The local associations are grouped into a national association, Association Nationale pour le Traitement à Domicile des Insuffisants Respiratoires (ANTADIR). In each local association, technicians visit the patients three or four times a year and at each visit they read the built-in time counter of the CPAP device to calculate the mean rate of use per day and report it to the physician who initially prescribed the treatment.

A nationwide survey of patients treated with CPAP for at least 6 months was initiated by ANTADIR in 1993 and conducted via the local associations. The aims of this study were to specify the sociodemographic characteristics of the patients receiving long-term treatment with CPAP, to analyse their perceived benefits, tolerance, compliance, overall satisfaction and quality of life.

\section{Methods}

The survey was conducted between June and September 1993. Questionnaires were mailed via the local associations 
to all patients registered with the participating associations who were started on nasal CPAP at home before January 1, 1993 and who were still on CPAP at the time of the survey.

The questionnaires comprised three sections: 1) a sociodemographic questionnaire (age, sex, marital status, educational level, socioprofessional activities); 2) a questionnaire on the perceived benefits, tolerance, compliance and overall satisfaction; and 3) a validated questionnaire on the quality of life (Nottingham Health Profile (NHP), part 1).

To evaluate the modification of the symptoms observed with nasal CPAP, patients were asked questions on snoring, fragmented sleep, restless sleep, daytime sleepiness, fatigue, irritability and morning headache. The possible answers were: "greatly decreased", "decreased", "unchanged", "increased" and "greatly increased", or "not concerned" or "don't know" for each parameter. Patients were also asked to indicate the three main improvements that they had perceived from the treatment, from 12 proposed answers.

To evaluate the tolerance of nasal CPAP, patients were asked questions on possible side-effects of nasal CPAP, tolerance to the nasal mask and the disturbance related to the noise of the device for themselves and their bedpartner. The subjective compliance was evaluated by the following two questions: 1) Do you use your nasal CPAP every night? If not, how many nights a week do you use it? 2) Do you use your nasal CPAP all night long? If not, how many hours a night do you use it? The overall satisfaction with the treatment and with the CPAP device was also investigated.

Quality of life was assessed using the NHP [18], translated and validated in French [19]. The first part of the NHP was used, which includes 38 items exploring six dimensions of perceived health: energy, pain, sleep, physical mobility, emotional reactions and social isolation. For each item the answer is yes $(=1)$ or no $(=0)$. Each item is weighted and a final score is calculated for each dimension by adding the weighted answer of each item. For each dimension, the score ranges from 0 (excellent perception of health) to 100 (very poor perception of health). The results of the NHP in an age-matched control population of 611 (298 males, 313 females) healthy subjects aged 45-64 yrs, were provided by A. Leplège (Inserm, U292, Le Kremlin-Bicêtre, France).

The patients returned their questionnaires to the local association and the technicians added to the questionnaire a record providing details of the machine used by the patients, the level of pressure and the readings of the time counter to enable calculation of the rate of use. The rate of use was calculated from the last two records of the time counter during the 6 months preceding the questionnaire. Compliance was calculated as the difference between two readings of the time counter, divided by the number of days separating the two readings.

\section{Statistical analysis}

All questionnaire responses were tabulated. The statistical analysis was performed by a statistician from the CRESGE (Centre de Recherches Economiques Sociologiques et de Gestion (CRESGE). The frequency of individual responses was counted. Comparison of the distribution of patients between groups was performed using the test of equality of proportions and the Mann-Whitney test. Mean values were compared using the Student's t-test or the Kolmogorov-Smirnov test for the NHP scores. Two-tailed p-values $<0.05$ were considered significant.

\section{Results}

\section{Description of the population}

Twenty-eight of the 32 local associations participated in the study. At the time of the survey, 5,339 patients had been using CPAP treatment for at least 6 months within these associations. Of these, 3,593 patients (67\%) answered the questionnaire but 368 questionnaires were rejected because of missing data, mainly the lack of time counter readings. Thus, 3,225 questionnaires were analysed. The mean number of patients included in each association was 115 (range 6-402).

The population included 2,796 males (87\%) and 429 females $(13 \%)$. Their mean age was $59 \pm 11$ yrs (median 60 yrs) and $52 \%$ were aged $>59$ yrs. Eighty per cent of the patients were married or cohabiting. This percentage is significantly higher than in the general French population over 40 yrs, where the percentage was $70 \%(p<0.05)$ [20]. The educational level of the patients differed from that of the French population by the small number of subjects without any diploma $(4.5 \%$ in the study population and $34 \%$ in the French population; $p<0.01)$. Twenty-two per cent of the patients had graduated from high school. The proportion of patients living in a rural area was $38 \%$. Twenty-nine per cent of the patients lived in an urban area of more than 50,000 inhabitants. The socioprofessional activities of the population did not differ from the general population, except for the proportion of white-collar employees, which was lower in the sample than in the general French population (14 versus 26.5\%; p<0.05) [21]. Thirty-two per cent of the patients still had a professional activity at the time of the survey.

Treatment had been used for longer than $1 \mathrm{yr}$ by $78 \%$ of the patients and for $>4$ yrs by $9 \%$. The mean CPAP level was $9.9 \pm 2.4 \mathrm{cmH}_{2} \mathrm{O}$. Pressure ranged $8-12 \mathrm{cmH}_{2} \mathrm{O}$ in $72 \%$ of the patients. It was $<8 \mathrm{cmH}_{2} \mathrm{O}$ in $14.6 \%$ and $>12$ for $13.4 \%$ of patients (fig. 1). Twelve CPAP devices from six different companies were used. A humidifier was used by $18 \%$ of the patients. The CPAP device had been changed in $37 \%$ of the patients. The main reasons were CPAP dysfunction, the noise of the blower and the prescription of devices including a humidifier. Most patients used a standard nasal mask, 5\% used an airway delivery and management (ADAM) circuit and $11 \%$ of the patients used individually moulded nasal masks.

\section{Efficacy}

Assessment of changes in symptoms with CPAP showed that initially the patients were highly symptomatic. The frequency of the main symptoms before CPAP was $90 \%$ for snoring, fatigue and daytime sleepiness, $89 \%$ for fragmented sleep and $80 \%$ for restless sleep. Irritability or depression had been present in $57 \%$ of the population and morning headache had been less frequent (49\%). 


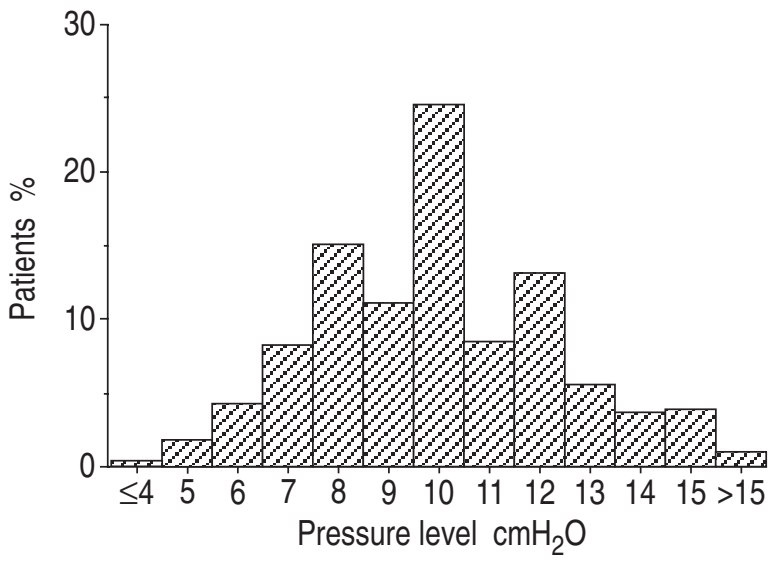

Fig. 1. - Distribution of patients according to the continuous positive airway pressure level $\left(\mathrm{cmH}_{2} \mathrm{O}\right)$ used at the time of the survey.

Sixty-nine per cent of the patients complained simultaneously of snoring, fatigue, daytime sleepiness, restless sleep and fragmented sleep prior to CPAP. Four of these five symptoms were present in $87 \%$ of the patients.

The percentage of patients who considered that their symptoms had decreased or greatly decreased owing to CPAP was $92 \%$ for snoring, $86 \%$ for daytime sleepiness, $83 \%$ for fatigue and restless sleep and $78 \%$ for fragmented sleep. An improvement in irritability or depression was reported by $65 \%$ of the patients. Morning headache was decreased in $66 \%$ of the patients (fig. 2). Three per cent of the patients reported no improvement in any symptom. The replies on the three main improvements perceived following treatment (table 1) showed that the most frequent answers were better quality of sleep, a reduction in snoring and a reduction in daytime sleepiness. Nearly $70 \%$ of the 1,028 patients at work considered that their work was easier since the treatment.

\section{Tolerance}

Tolerance to the nasal mask was good in $42 \%$ of the patients and very good in $15 \%$. It was poor or very poor in

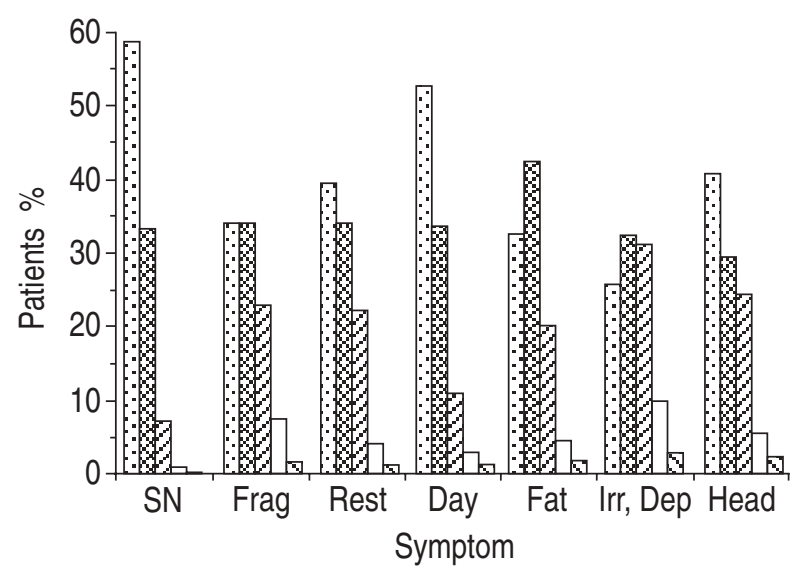

Fig. 2. - Changes in symptoms perceived by patients and attributed to continuous positive airway pressure treatment. $\because \because$ : greatly decreased $\$$ : decreased; $Q Z$ : unchanged; $\square$ : increased; $\$$ : greatly increased. SN: snoring; Frag: fragmented sleep; Rest: restless sleep; Day: daytime sleepiness; Fat: fatigue; Irr, Dep: irritability or depression; Head: morning headache.
Table 1. - Main improvements perceived by the patients treated with continuous positive airway pressure (CPAP) for at least 6 months

\begin{tabular}{lc}
\hline Proposed answers & $\begin{array}{c}\text { Percentage of } \\
\text { patients mentioning } \\
\text { this answer }\end{array}$ \\
\hline I have a better quality of sleep & 55 \\
I feel more refreshed when I wake up & 31 \\
I feel less tired during the day & 22 \\
I feel less sleepy during the day & 42 \\
I feel in better condition during the day & 22 \\
I am less irritable, I am in a better mood & 6 \\
I have a better memory & 5 \\
I breathe more easily & 28 \\
My sleep is less fragmented & 13 \\
I feel more secure while driving & 23 \\
My snoring has decreased & 45 \\
My sexual activity has improved & 3 \\
\hline Patients were asked to montion
\end{tabular}

Patients were asked to mention the three main improvements they had perceived from their CPAP treatment.

$9 \%$. The two most frequent complaints were dry mouth and throat $(52.2 \%)$ and, for patients who did not live alone, the noise of the blower disturbing their bedpartner (47\%). Many patients complained of side-effects related to the nose: congestion (26\%), soreness (27\%) and drippy nose $(24 \%)$. Red eyes or conjunctivitis were reported by $28 \%$ of the population. The blower was too noisy for $15 \%$ of the patients themselves. There was no difference in the frequency of most of the complaints between patients treated for $<1 \mathrm{yr}$ and patients treated for a longer time. However, a drippy nose was more frequent in patients treated for $>1$ yr than in patients treated for $<1$ yr $(\mathrm{p}<$ 0.05 ). The pressure level had some influence on two complaints: a dry mouth and a drippy nose were more frequent in patients with a pressure level $>12 \mathrm{cmH}_{2} \mathrm{O}$ than in patients with a pressure $<8 \mathrm{cmH}_{2} \mathrm{O}$.

\section{Compliance and overall satisfaction}

Responses to the questionnaire evaluating compliance showed that $89 \%$ of the patients reported that they used their CPAP every night. The others said that they used it on average for 4 nights a week. Usage of the CPAP all night long was reported by $76 \%$ of the patients. Those who did not, said they used it for $5 \mathrm{~h}$ a night. Good compliance, i.e. every night and all night long, was reported by $73 \%$ of the respondents and poor compliance, i.e. neither every night nor all night long, by $8 \%$ of them. Readings of the built-in time counter showed a mean rate of use for the whole responding population of $6 \mathrm{~h} 36 \mathrm{~min} \pm 2 \mathrm{~h} 15 \mathrm{~min}$. The rate of use was longer than $4 \mathrm{~h} \cdot$ night $^{-1}$ for $86 \%$ of the patients (fig. 3). There was a good agreement between the patients' reported compliance and the use calculated from the time counter. Patients with good self-reported compliance had a mean rate of use of $7 \mathrm{~h} 17 \mathrm{~min}$. The rate of use was $5 \mathrm{~h} 10 \mathrm{~min}$ for patients who reported intermediate compliance, i.e. either every night but not all night long or not every night but all night long, and $3 \mathrm{~h} 30 \mathrm{~min}$ for patients with poor compliance (table 2 ). There was a significant relationship between the objective compliance calculated from the time counter and the improvement in symptoms and the tolerance of the treatment (table 3 ). Patients who reported a great improvement in snoring and 


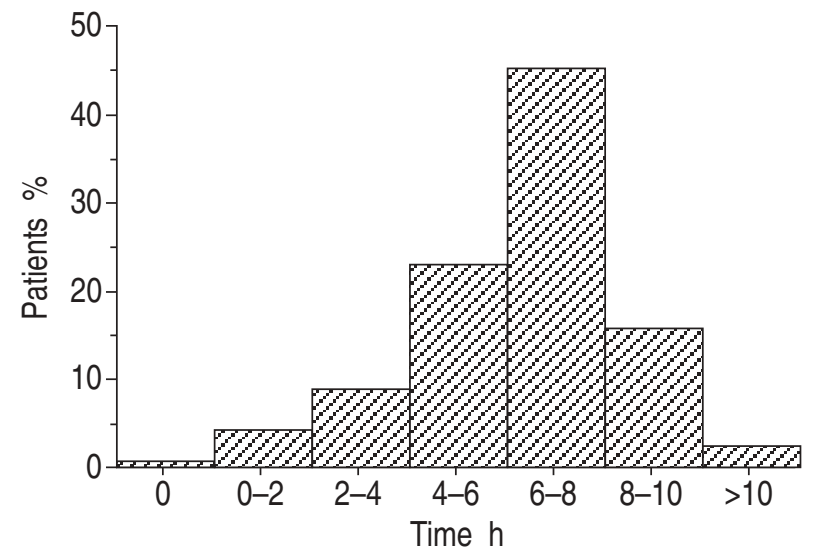

Fig. 3. - Compliance (mean daily rate of use) calculated from the time counter.

Table 2. - Comparison between the self-reported use and the daily use rate calculated from the time counter

\begin{tabular}{lcc}
\hline & All night long & Not all night long \\
\hline Every night & $\mathrm{n}=2360(73 \%)$ & $\mathrm{n}=512(16 \%)$ \\
& $7 \mathrm{~h} 17 \mathrm{~min}$ & $5 \mathrm{~h} 10 \mathrm{~min}$ \\
& $(1 \mathrm{~h} 47 \mathrm{~min})$ & $(1 \mathrm{~h} 51 \mathrm{~min})$ \\
Not every night & $\mathrm{n}=104(3 \%)$ & $\mathrm{n}=248(8 \%)$ \\
& $5 \mathrm{~h} 10 \mathrm{~min}$ & $3 \mathrm{~h} \mathrm{30} \mathrm{min}$ \\
& $(2 \mathrm{~h} 33 \mathrm{~min})$ & $(2 \mathrm{~h} 13 \mathrm{~min})$ \\
\hline
\end{tabular}

For each answer, the first number represents the number of patients (\% of the population) and the second number indicates the mean daily use rate calculated from the time counter (SD).

Table 3. - Relationship between the objective compliance and the improvement in symptoms, tolerance and overall satisfaction

\begin{tabular}{|c|c|c|c|c|}
\hline & & \multicolumn{3}{|c|}{ Rate of use per night* } \\
\hline & & $<4 \mathrm{~h}$ & $4-7 \mathrm{~h}$ & Š7 h \\
\hline & $\mathrm{n}^{+}$ & $\%$ & $\%$ & $\%$ \\
\hline \multicolumn{5}{|l|}{ Snoring } \\
\hline Greatly decreased & 1703 & 9 & 43 & 48 \\
\hline Other responses & 1197 & 21 & 43 & 35 \\
\hline \multicolumn{5}{|l|}{ Daytime sleepiness } \\
\hline Greatly decreased & 1511 & 10 & 44 & 46 \\
\hline Other responses & 1379 & 19 & 43 & 39 \\
\hline \multicolumn{5}{|l|}{ Fatigue } \\
\hline Greatly decreased & 938 & 11 & 45 & 45 \\
\hline Other responses & 2002 & 17 & 42 & 41 \\
\hline \multicolumn{5}{|l|}{ Mask tolerance } \\
\hline Very good or good & 1826 & 9 & 42 & 49 \\
\hline Other responses & 1377 & 20 & 45 & 35 \\
\hline \multicolumn{5}{|c|}{ Satisfaction with the device } \\
\hline Very satisfied & 1007 & 7 & 40 & 53 \\
\hline Other responses & 2197 & 17 & 45 & 39 \\
\hline \multicolumn{5}{|c|}{ Satisfaction with the therapy } \\
\hline Very satisfied & 1184 & 8 & 41 & 51 \\
\hline Other responses & 2021 & 17 & 45 & 38 \\
\hline
\end{tabular}

*: The rate of use was calculated from the time counter. ${ }^{+}$: number of patients giving the corresponding answer. For each item the sum of the two numbers is not equal to 3,225 patients as some patients did not answer the item. $\sharp$ for each compliance category, the number of patients is expressed as a percentage of the total number of patients who gave the same response to the questionnaire. daytime sleepiness had a better compliance than patients whose snoring or daytime sleepiness was less reduced or unchanged or increased $(\mathrm{p}<0.01)$. Good or very good tolerance to the nasal mask was also associated with better compliance $(p<0.01)$. There was no influence of the pressure level on the compliance.

The overall satisfaction with the CPAP device was good for $59 \%$ and very good for $31 \%$ of the patients. Eight per cent of the patients could not say whether they were satisfied or not. The overall satisfaction with the results of the treatment was even greater, as $93 \%$ of the patients were satisfied or very satisfied. Six per cent were neither satisfied nor unsatisfied. The overall satisfaction was significantly correlated with the compliance $(\mathrm{p}<0.01)$ (table 3 ).

\section{Nottingham Health Profile}

Among the 38 items of the NHP, the most frequent answers were: "I soon run out of energy" (55\% of patients), "I find it hard to stand for long" (46\%), "I have trouble getting up and downstairs" (46\%) and "I find it hard to bend" (45\%). The lowest score (9.9) was observed for the dimension of social isolation. The worst perceived dimension was energy, with a mean score of 33.6. The scores were 21.4 for physical mobility, 19.2 for sleep, 17.7 for pain and 13.8 for emotional reactions. Fifteen per cent of the patients had a very bad perception of the dimension energy, with a score of 100, whereas the percentage of patients with a score of 100 in the other dimensions was $<2.5 \%$ (fig. 4). The percentage of patients with a rather good perception of their status (score <50) was $77 \%$ for physical mobility and $92 \%$ for emotional reactions. The percentage of patients with a very good perception, i.e. a score of 0 , was only $25 \%$ for physical mobility. It ranged $40-50 \%$ for energy, sleep, pain and emotional reactions and reached $74 \%$ for social isolation. On average, OSAS patients treated with CPAP had a good perception of their health, with a score of 0 in at least four of six dimensions in $40 \%$ of the patients.

Patients older than $60 \mathrm{yrs}$ had a poorer perception of their health than patients $<60$ yrs old. The score was significantly higher for energy, physical mobility, sleep, pain

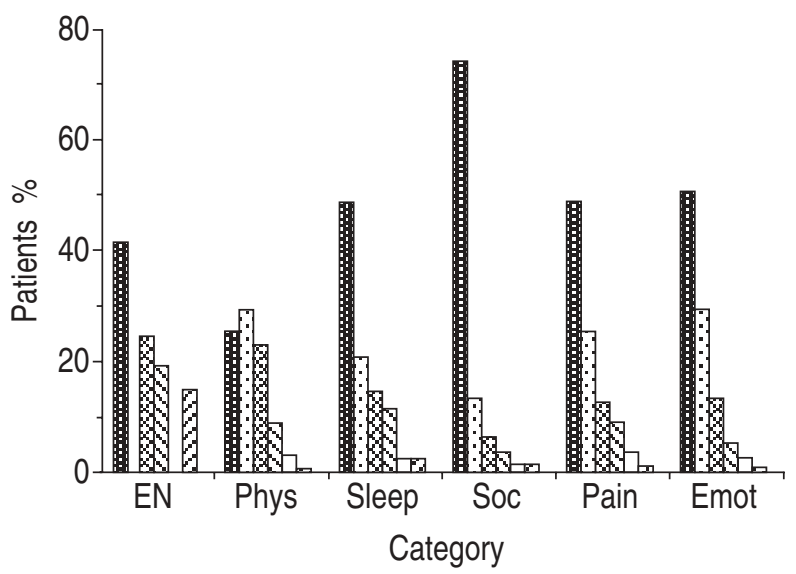

Fig. 4. - Distribution of patients in each dimension of the Nottingham Health Profile according to score categories. 睥: $0 ; \because \because ;: 0-25 ; \circledast$ : 25-50; \$: 50-75; $\square: 75-100 ; \angle 2: 100$. EN: energy; Phys: physical mobility; Soc: social isolation; Emot: emotional reactions. There was no patient in the score categories 0-25 and 75-100 for EN. 
and social isolation $(\mathrm{p}<0.01)$. They had a better perception of emotional reactions $(\mathrm{p}<0.01)$.

Females with OSAS treated with CPAP had a poorer perception of their health than males. The mean score for energy was $31.8 \pm 35.4$ for males and $45.2 \pm 38.3$ for females $(\mathrm{p}<0.01)$. The difference between males and females was significant for each dimension, even on the best

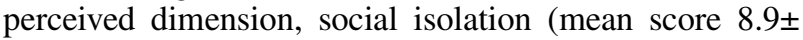
19.4 for males and $16.3 \pm 24.4$ for females; $p<0.01$ ). The percentage of patients who did not feel isolated at all was $76 \%$ in males and only $61 \%$ in females $(\mathrm{p}<0.01)$. A comparison of healthy subjects aged 45-64 yrs with patients of the present population within the same age range showed that females and males treated with CPAP had a poorer perception of their health than normal controls. The difference in the mean score was significant for each dimension for females $(\mathrm{p}<0.01)$ (fig. 5a) and for energy, physical mobility, sleep and social isolation $(\mathrm{p}<0.01)$ for males (fig. 5b). The greatest differences between our patients and healthy subjects were observed for energy and physical mobility. For the other dimensions, the difference was significant but small.

For each dimension, the perception of health was better for patients who were very satisfied with the treatment than for the others $(\mathrm{p}<0.01)$ and for patients who reported that their symptoms (snoring, daytime sleepiness, fatigue, restless sleep or fragmented sleep) were greatly reduced $(\mathrm{p}<0.01)$. Analysis of the quality of life with regard to the objective compliance (table 4) showed that patients with an intermediate compliance (use per night 4-7 h) had a
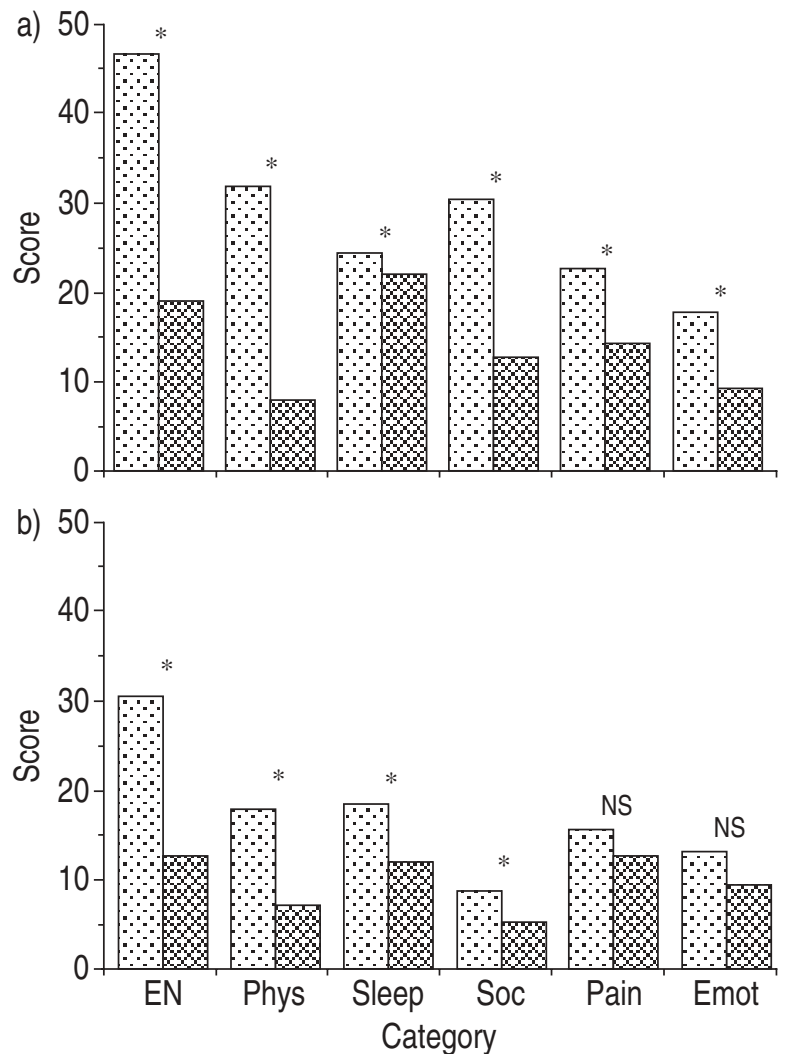

Fig. 5. - Comparison of the Nottingham Health Profile scores between healthy subjects aged 45-64 yrs ( $\because \because)$ and patients of the study population in the same age range (\$) for a) females and b) males. EN: energy; Phys: physical mobility; Soc: social isolation; Emot: emotional reactions. *: $\mathrm{p}<0.05$.
Table 4. - Relationship between the objective compliance and the perception of quality of life evaluated by the six dimensions explored by the Nottingham Health Profile

\begin{tabular}{lccc}
\hline & \multicolumn{3}{c}{ Rate of use per night* } \\
\cline { 2 - 4 } & $<4 \mathrm{~h}$ & $4-7 \mathrm{~h}$ & Š7 h \\
\hline $\begin{array}{l}\text { Energy } \\
\mathrm{n}\end{array}$ & 439 & 1380 & 1369 \\
$\quad$ mean score & $37.3 \pm 37.4 \dagger$ & $29.9 \pm 34.8^{\ddagger}$ & $35.9 \pm 36.3$ \\
Physical mobility & & & \\
$\quad \mathrm{n}$ & 437 & 1374 & 1367 \\
$\quad$ mean score & $23.2 \pm 24.3^{\dagger \dagger}$ & $18.5 \pm 21.3 \ddagger$ & $23.8 \pm 24.1$ \\
Sleep & & & \\
$\quad \mathrm{n}$ & 438 & 1380 & 1368 \\
$\quad$ mean score & $25.5 \pm 29.8^{\dagger \dagger}$ & $18.7 \pm 25.8$ & $17.7 \pm 24.3^{\#}$ \\
Social isolation & & & \\
$\quad \mathrm{n}$ & 437 & 1380 & 1369 \\
$\quad$ mean score & $11.6 \pm 21.5^{\dagger \dagger}$ & $8.3 \pm 19.2 \ddagger$ & $10.7 \pm 20.7$ \\
Pain & & & \\
$\quad \mathrm{n}$ & 438 & 1376 & 1361 \\
$\quad$ mean score & $19.5 \pm 26.4 \dagger$ & $15.9 \pm 23.2^{\ddagger \dagger}$ & $18.8 \pm 24.8$ \\
Emotional reactions & & & \\
$\quad \mathrm{n}$ & 436 & 1379 & 1365 \\
$\quad$ mean score & $16.5 \pm 22.8^{\dagger \dagger}$ & $12.5 \pm 19.2$ & $14.2 \pm 21.2^{\#}$ \\
\hline
\end{tabular}

*: The rate of use was calculated from the time counter. Comparison between patients with poor and intermediate compliance: ${ }^{\dagger} \mathrm{p}<0.05$; $\mathrm{p}<0.01$; between patients with intermediate and good compliance: $\mathrm{p}<0.01$; between patients with poor and good compliance: \#: $\mathrm{p}<0.05$, \#: $\mathrm{p}<0.01$.

better perception of their health than poorly compliant patients (use per night $<4 \mathrm{~h}$ ). They had also a better perception of their health than very compliant patients (use per night $>7 \mathrm{~h}$ ) in all dimensions except sleep. Very compliant patients differed from poorly compliant patients by a lower score, i.e. a better perception in emotional reactions $(\mathrm{p}<0.05)$ and sleep $(\mathrm{p}<0.01)$.

\section{Discussion}

This study of a population of more than 3,000 patients from different areas of France showed that more than 70\% of OSAS patients treated with CPAP for at least 6 months and who responded to the questionnaire had a good compliance with the treatment and that the compliance was related to the perceived benefits, tolerance and overall satisfaction with the treatment. Their general health status or quality of life, although good, remained lower than that of healthy subjects.

This retrospective study aimed to describe a nationwide population of patients who were treated with CPAP in France. This survey was conducted via the local associations delivering the CPAP devices. The CPAP treatment was prescribed by physicians whose criteria for deciding to treat with CPAP were not known from the associations. However, in France, at the time of the survey, there was no apnoea/hypopnoea index (AHI) criterion for reimbursement of CPAP by the social security system. No information could be obtained on the percentage of patients who refused home treatment with CPAP. To have an idea of the percentage of patients who abandoned their treatment, data from the ANTADIR Observatory, which regroups 25 local associations, were analysed. Between 1985 and December 1992 nasal CPAP was installed at home in 5,283 patients. 
During this period, 750 (14\%) discontinued their treatment. As 23 of these associations participated in the present survey, this percentage can be assumed to be representative of the French patients treated via the local associations.

This retrospective study may be affected by bias inherent in this kind of study. The patients who returned questionnaires (67\%) might be the most compliant and satisfied patients, as suggested by HOFFSTEIN et al. [9]. To evaluate this bias, the results from 12 associations (1,541 patients) where the response rate was at least $75 \%$ (mean response rate $84 \%$ ) were compared with the results from 16 associations (1,684 patients) where the response rate was lower than $75 \%$ (mean response rate $51 \%$ ). A low response rate was not associated with a greater improvement in symptoms or a higher compliance or a better quality of life. Even though this bias cannot be completely excluded, the difference in the response rate between the 28 associations does not appear to be related to patient compliance and satisfaction.

The daily rate of use by each patient was assessed from the time counter and calculated from the last two records before the survey. Thus, the time for which the CPAP unit power was on was calculated. It has already been shown that the effective use (time for which the effective pressure was applied) represents $89-97 \%$ of the running time [13, $14,16,22]$. It was found that $2,783(86 \%)$ patients who responded had a CPAP rate of use $>4 \mathrm{~h}$. In 95 patients treated for at least $1 \mathrm{yr}$, PIETERS et al. [23] found that 74\% of patients used their CPAP device for $>4 \mathrm{~h} \cdot$ night $^{-1}$. Considering the worst hypothesis, i.e. that all patients who did not respond had a poor compliance, the percentage of the whole population $(5,339$ patients) using their CPAP device for at least $4 \mathrm{~h} \cdot$ night $^{-1}$ will be $52 \%$. This hypothesis was considered to be unlikely as the mean daily use rate observed in this population ( $6 \mathrm{~h} 36 \mathrm{~min}$ ) was similar to the compliance observed in other studies [8,23-26] and especially in studies $[15,22]$ on patients who did not reject the treatment early on and were treated chronically $(6.5 \mathrm{~h}$ and $7.1 \mathrm{~h}$, respectively).

The present study does not provide information on the compliance with CPAP of OSAS patients in general, but on patients chronically treated and who did not reject the treatment. The patients were treated for at least 6 months and $78 \%$ for $>1 \mathrm{yr}$. Thus, neither patients with very poor compliance who usually discontinued CPAP during the initial period of treatment, i.e. after 4 months or less of treatment $[7,9,27]$, nor patients who rejected their treatment later on were included in this study. This may explain the low percentage of patients who perceived no benefits at all from the treatment (3\%). The percentage of patients continuing treatment whilst they perceived no benefits is similar to percentages observed in other studies on chronically treated patients, which were 6.4\% [9] and $1 \%$ [15]. A relationship was found between the rate of use measured by the time counter and the improvement in symptoms and, particularly, in daytime sleepiness and snoring. This link between compliance and perceived benefits has been observed in previous studies $[7,9,10,24$, 26].

Most of the complaints were related to nasal problems, but also to the noise of the blower, which disturbed the bedpartner. More than $50 \%$ of the patients had experienced at least one nasal problem since they started CPAP treatment. These side-effects do not appear to change over time as the percentage of patients complaining of sideeffects was similar in patients treated for less and for $>1$ yr, with one exception: the frequency of drippy nose was greater in patients treated for $>1 \mathrm{yr}$. Such a high percentage of side-effects has been reported previously $[9,15,24]$ and it is not surprising that they affect the compliance. There was a higher rate of use in patients who reported good or very good tolerance to the nasal mask. Indeed, mask intolerance has been shown, together with the lack of perceived benefits, as one of the main reasons for discontinuing CPAP [7].

Despite the high percentage of side-effects and the discomfort due to the mask, most patients who responded to the questionnaire were satisfied or very satisfied with either the CPAP device or the results of the therapy. In this population treated with nasal CPAP for at least 6 months and up to $8 \mathrm{yrs}$, satisfaction with the treatment reached 93\%. Long-term compliance with CPAP was also related to the degree of satisfaction. KRIBBS et al. [16] also found a better satisfaction score in regular users of CPAP than in irregular users.

No influence of the pressure level was found, either on the perceived benefits, the tolerance, the compliance or the overall satisfaction with the treatment. These results are consistent with a previous report [15]. Thus, the clinical usefulness of "intelligent" CPAP designed to deliver the lowest possible pressure to prevent respiratory disorders $[28,29]$ remains to be evaluated.

Very few studies have assessed the quality of life of patients with OSAS before treatment [17] or the influence of CPAP treatment on quality of life $[14,30]$. KRIBBS et al. [30] used the sickness impact profile to measure health rating and found an improvement from pretreatment to post-treatment after a mean treatment duration of 2-3 months. ENGLEMAN et al. [14] used part 2 of the NHP to evaluate the influence of 4 weeks' treatment with nasal CPAP. They found an improvement in the social life, sex life and ability to carry out domestic chores. In the present study, the quality of life of patients treated with CPAP was evaluated using part 1 of the NHP. This general health-status questionnaire investigates multiple dimensions of health that may be affected by OSAS, e.g. sleep and energy. It is simple and most patients are able to complete the questionnaire in a few minutes. It has been translated and validated in French and data from healthy French subjects are available.

This questionnaire has also been used by ForNAs et al. [17] in untreated OSAS patients. They showed that OSAS patients had a poorer perception of their health than control subjects in all NHP dimensions except for emotional reactions. The worst perceived dimensions were energy, sleep and emotional reactions. In treated patients energy was also found to be the worst perceived dimension. However, the results indicate that OSAS patients treated with CPAP have a rather good perception of their health, as the mean score was lower than 25 for all dimensions except for energy and $40 \%$ of the patients had a score of 0 in at least four of six dimensions. Comparison of the present population with the untreated population studied by FoRNAS et al. [17] is difficult as they did not calculate weighted scores. Furthermore, their control group was composed of 40 nonsnoring healthy subjects who were not randomly selected and not representative of the general population. 
The two studies evaluating pretreatment and post-treatment quality of life in OSAS using different questionnaires $[14,30]$ showed an improvement with CPAP treatment but did not compare the study population to healthy subjects. Comparison between healthy subjects and our patients within the same age range shows that patients with OSAS treated with CPAP have a different perception of their health. The main differences are observed for energy and physical mobility, and social isolation for females. In the present study population, females had a more negative perception of their health than males. However, this difference between females and males is also observed in healthy subjects. The difference in the quality of life between OSAS patients and healthy subjects might be related to conditions usually associated with OSAS, such as obesity, hypertension, cardiovascular diseases and diabetes.

A relationship was also found between the quality of life and the perceived benefits and overall satisfaction with the treatment. Patients whose symptoms were greatly improved and who were very satisfied with the treatment had a better perception of their health than the other patients. The relationship between quality of life and compliance is less clear, as quality of life was better in patients with intermediate compliance than in patients with good compliance and quality of life of very compliant patients was different from poorly compliant patients for only sleep and emotional reactions. It can be speculated that very compliant patients, who are often patients with more severe OSAS $[6,9,13,30]$ and are usually more obese $[6$, 9], more frequently have associated diseases and that in these subjects sleep apnoea is not the only condition that may affect perceived health.

From these findings on a very large population of patients with obstructive sleep apnoea syndrome treated with continuous positive airway pressure and who continued their treatment for 6 months or longer, it can be concluded that, despite the constraints and side-effects of the treatment, patients reported a relatively good perception of their health were usually satisfied with the treatment. Chronic daily use was influenced by the perceived improvement in symptoms, tolerance to the nasal mask and overall satisfaction. The perceived benefits also influenced quality of life. The results on quality of life of patients treated with continuous positive airway pressure suggest that this criterion should be evaluated on a prospective basis in patients with obstructive sleep apnoea syndrome.

Acknowledgements: The authors thank M. CoisyVialettes for data collection and study coordination, D. Veale for help with the manuscript and the local respiratory home care associations for the recording and transmission of data.

\section{References}

1. Sullivan CE, Berthon-Jones M, Issa FG, et al. Reversal of obstructive sleep apnea by continuous positive airway pressure applied through the nares. Lancet 1981; i: 862-865.

2. Sullivan CE, Issa FG, Berthon-Jones M, et al. Home treatment of obstructive sleep apnea with continuous pos- itive airway pressure applied through a nose mask. Bull Eur Physiopathol Respir 1984; 20: 49-54.

3. Sanders MH, Moore SE, Eveslage J. CPAP via nasal mask: a treatment for obstructive sleep apnea. Chest 1983; 83: 144-145.

4. Berry RB, Block AJ. Positive nasal airway pressure eliminates snoring as well as sleep apnea. Chest 1984; 85: 1520.

5. Rajagopal KR, Bennett LL, Dillard TA, et al. Overnight nasal CPAP improves hypersomnolence in obstructive sleep apnoea. Chest 1986; 90: 172-176.

6. Nino-Murcia G, McCann CC, Bliwise DL, et al. Compliance and side effects in sleep apnea patients treated with nasal continuous positive airway pressure. West J Med 1989; 150: 165-169.

7. Rolfe I, Olson G, Saunders NA. Long-term acceptance of continuous positive airway pressure in obstructive sleep apnea. Am Rev Respir Dis 1991; 144: 1130-1133.

8. Krieger J, Kurtz D. Objective measurement of compliance with nasal CPAP treatment for obstructive sleep apnea syndrome. Eur Respir J 1988; 1: 436-438.

9. Hoffstein V, Viner S, Mateika S, et al. Treatment of obstructive sleep apnea with nasal continuous positive airway pressure: patient compliance, perception of benefits and side effects. Am Rev Respir Dis 1992; 145: 841-845.

10. Waldhorn RE, Herrick TW, Nguyen MC, et al. Long-term compliance with nasal continuous positive airway pressure therapy of obstructive sleep apnea. Chest 1990; 97: 33-38.

11. Rauscher H, Popp W, Wanke T, Zwick H. Acceptance of CPAP therapy for sleep apnea. Chest 1991; 100: 1019_ 1023.

12. Krieger J. Long-term compliance with nasal continuous positive airway pressure (CPAP) in obstructive sleep apnea patients and non apneic snorers. Sleep 1992; 15: s42-s46.

13. Reeves-Hoche MK, Meck R, Zwillich CW. Nasal CPAP: an objective evaluation of patient compliance. Am J Respir Crit Care Med 1994; 149: 149-154.

14. Engleman HM, Martin SE, Douglas NJ. Compliance with CPAP therapy in patients with the sleep apnoea/hypopnea syndrome. Thorax 1994; 49: 263-266.

15. Pépin J-L, Léger P, Veale D, et al. Side effects of nasal continuous positive airway pressure in sleep apnea syndrome: study of 193 patients in two French sleep centers. Chest 1995; 107: 375-381.

16. Kribbs NB, Pack AI, Kline LR, et al. Objective measurement of patterns of nasal CPAP use by patients with obstructive sleep apnea. Am Rev Respir Dis 1993; 147: 887-895.

17. Fornas C, Ballester E, Arteta E, et al. Measurement of general health status in obstructive sleep apnea hypopnea patients. Sleep 1995; 18: 876-879.

18. Hunt SM, McEwen J, McKenna SP. Perceived health; age and sex comparisons in a community. $J$ Epidemiol Commun Health 1984; 38: 156-160.

19. Bucquet D, Condon S. Adaptation en Français du Nottingham Health Profile et caractéristiques opératoires de la version Française. Montpellier, INSERM (CJF 88-12) March 1990.

20. Institut National de la Statistique et des Études Economiques. "Population - Activité - Ménages". Recensement général de la population Française de plus de 40 ans, 1990. Paris, INSEE, 1992.

21. Institut National de la Statistique et des Études Economiques. Tapiero M, Mary S, Meyer C, Thibaudeau P. Tableaux de l'économie Française, 1992-1993. Paris, INSEE, 1992. 
22. Fleury B, Rakotonanahary D, Hausser-Hauw C, Lebeau B, Guilleminault C. Objective patient compliance in longterm use of nCPAP. Eur Respir J 1996; 9: 2356-2359.

23. Pieters T, Collard P, Aubert G, et al. Acceptance and long-term compliance with nCPAP in patients with obstructive sleep apnoea syndrome. Eur Respir J 1996; 9: 939-944.

24. Meurice JC, Dore P, Paquereau J, et al. Predictive factors of long-term compliance with nasal continuous positive airway pressure treatment in sleep apnea syndrome. Chest 1994; 105: 429-433.

25. Fletcher EC, Luckett RT. The effect of positive reinforcement on hourly compliance in nasal continuous positive airway pressure users with obstructive apnea. Am Rev Respir Dis 1991; 143: 936-941.

26. Engleman HM, Asgari-Jirhandeh N, McLeod AL, et al.
Self-reported use of CPAP and benefits of CPAP therapy. Chest 1996; 109: 1470-1476.

27. Schweitzer P, Chambers G, Birkenmeier N, et al. Nasal continuous airway pressure (CPAP) compliance at six, twelve and eighteen months (Abstract). Sleep Res 1987; 16: 186.

28. Teschler H, Berthon-Jones M, Thompson AB, Henkel A, Henry J, Konietzko N. Automated continuous positive airway pressure titration for obstructive sleep apnea syndrome. Am J Respir Crit Care Med 1996; 154: 734-740.

29. Robert D, Banfi P, Leger P, et al. Comparison of automatic continuous adjust CPAP versus constant CPAP in OSAS. Am J Respir Crit Care Med 1994; 149: A497.

30. Kribbs NB, Pack AI, Kline LR, et al. Effects of one night without nasal CPAP treatment on sleep and sleepiness in patients with obstructive sleep apnea. Am Rev Respir Dis 1993; 147: 1162-1168. 